\title{
North-South Scholarly Collaboration: Opportunities and Experiences in Africa
}

\author{
Diane H. Sonnenwald \\ UCD, Ireland \\ Sonnenwald Associates \\ diane.sonnenwald@ucd.ie \\ Heidi Julien \\ University at Buffalo, USA and \\ University of Pretoria \\ heidijul@buffalo.edu
}

\author{
Abebe Rorissa \\ University of Tennessee, \\ Knoxville, USA \\ arorissa@utk.edu \\ Jaya Raju \\ University of Cape Town, \\ South Africa \\ jaya.raju@uct.ac.za
}

\author{
Ina Fourie \\ University of Pretoria, South Africa \\ ina.fourie@up.ac.za \\ Daniel Alemneh \\ University of North Texas, USA \\ Daniel.Alemneh@unt.edu
}

\begin{abstract}
North-South scholarly collaboration and academic exchange programs help to address the challenges experienced by developing countries in Africa and elsewhere, and provide unique benefits to scholars in developed countries. Many academics in the global north, however, have limited, or no, information about opportunities to visit academics and institutions in developing countries and those in such countries in the global south do not have contacts to whom they can reach out. The intention of the panel is to stimulate future north-south collaborations by increasing awareness of both funded opportunities and low budget initiatives for scholarly exchanges and collaborations, benefits for scholars and their institutions in developed and developing countries, and best practices with respect to north-south collaborations and scholarly exchanges. This panel is sponsored by the Africa Chapter and SIG-III.
\end{abstract}

\section{KEYWORDS}

Developing countries; Knowledge sharing; North-South collaboration; Scholarly exchange programs; Scholarly collaboration

\section{INTRODUCTION}

A goal in the ASIS\&T strategic plan (2020) is to improve knowledge sharing opportunities through various means (see GOAL \#3). This goal supports ASIS\&T's mission and vision of a community of researchers and practitioners in information science and technology, and reflects its values of knowledge sharing, equity, diversity and inclusion. One of the ways to achieve this goal, while also providing multiple benefits to ASIS\&T members from both developed and developing countries, are formal and informal north-south collaborations among members through schemes such as visiting professor positions, scholarly exchange programs and mobility programs. These and similar national and university programs foster collaboration across cultural and national boundaries and increase our understanding concerning equity, diversity, inclusion, justice, as well as research and teaching contexts and approaches. For example, opportunities to address gender and ethnic inequities and marginalization can be created (Taba et al., 2019).

Collaborations, including sharing expertise on teaching, publication, postgraduate supervision and grant applications, are especially valuable to developing countries (Garcia-Sanchez et al., 2019; Skandhan \& Apodaca, 2020). Similarly, collaborations can provide inspiration for new research questions, access to study populations including indigenous communities (Windchief \& Ryan, 2019), and opportunities to learn different teaching techniques for scholars in developed countries. Although collaborations provide much value, challenges (Stupak, 1979), careful planning and preparation, management of expected outcomes (Byrne, 1998) must be addressed. Cultural sensitivity and awareness and socialization experiences should also be addressed (Haussler et al. 2003; Xue et al., 2015). A summary of benefits, challenges and stages of scientific collaborations can be found in Sonnenwald (2007).

Collaborations, especially those across geographic, institutional and cultural boundaries, can be facilitated through participation in scholarly exchange and mobility programs. Longer-term visits help members from developing and developed nations build trust relationships that provide a foundation for effective collaboration (Sonnenwald, 2007).

$84^{\text {th }}$ Annual Meeting of the Association for Information Science \& Technology | Oct. 29 - Nov. 3, 2021| Salt Lake City, UT. Author(s) retain copyright, but ASIS\&T receives an exclusive publication license. 
For example, cognitive trust focusing on judgments of competence and reliability, and affective trust focusing on interpersonal bonds and perceptions of colleagues' motivations, intentions and ethics are essential for effective collaboration (Sonnenwald, 2003; 2005). It typically takes time to build cognitive and affective trust, and one of the most efficient ways to do this is through extended face-to-face interaction. Face-to-face interaction can be achieved through visiting positions, e.g., as evidenced by the Erasmus+ program (European Union, n.d.), Fulbright U.S. Scholar Program (Fulbright Commission, n.d.), and universities' exchange programs including visiting professor and academic exchange programs, the appointment of adjunct professors, mutual degree programs, and memoranda of understanding between academic departments and institutions.

Although the practice of visiting scholars and exchange programs is not new (e.g., Beck, 1987; Calhoun, et al., 1980; Dubinsky, 2014) and the benefits and challenges have been discussed in general (e.g., Beeler et al., 2020; Boudreau \& Waschke, 2015) and in specific fields such as the health sciences (Shah, et al., 2020; Sayyid et al., 2019), there is no research focusing on visiting scholar and exchange programs and participants' experiences in Information Science and initiatives in Africa.

As the world emerges from the global Covid-19 pandemic and with the ASIS\&T Africa Chapter firmly established with approximately 240 members as of March 2021, a panel discussion on academic exchange and mobility program opportunities with universities in Africa is timely. Many scholars outside Africa do not know about visiting positions across Africa or the options that might be available to enable face-to-face interaction and visits. This lack of knowledge ranges from practical issues (e.g., academic calendars, the assistance concerning local housing and local health care, funding) to professional issues (e.g., career and personal benefits from participation, work expectations, availability of local colleagues for research discussions/collaborations, and possible student interaction.) This panel will address these issues from the perspective of scholars in Africa who have hosted scholars from developed countries and who have created exchange programs that host scholars from developed countries, and from the perspective of scholars in developed countries who have participated in scholarly exchange programs in Africa.

This panel is sponsored by the Africa Chapter and SIG-III.

\section{PANEL ORGANIZATION}

This panel brings together academics who recognize the need to increase face-to-face visits and strengthen collaboration between global north-south academics and institutions. It includes academics from developing countries who can offer visiting opportunities, and academics from developed countries who have had visiting appointments and collaboration with institutions and colleagues in developing countries.

The moderator, Sonnenwald, will first introduce the rationale for the panel and each panelist. Second, each panelist will share their perspectives and experiences with north-south exchange programs and collaborations as follows.

\section{Opportunities and experiences from a developing country perspective - University of Pretoria. Ina Fourie}

Fourie will share her personal experiences and experiences within the Department of Information Science hosting and collaborating with academics from the UK and USA at the University of Pretoria in South Africa. She will also present scholarly exchange programs available at the University of Pretoria, including well-funded and low-budget initiatives, and motivations for participating in these programs. (10 minutes)

Opportunities and experiences from a developing country perspective - University of Cape Town. Jaya Raju

Raju will share her personal experiences and that of academics within the Department of Knowledge and Information Stewardship in collaborating with international colleagues, hosting visitors at the University of Cape Town in South Africa, and being hosted as visitors in developed country institutions. She will also present the scholarly exchange opportunities available at the University of Cape Town as well as the challenges of maintaining equitable and inclusive north-south scholarly exchange and collaborative initiatives. (10 minutes)

\section{Experiences as a visiting scholar in South Africa. Heidi Julien}

Julien will share her experiences as a visiting scholar at the University of Pretoria (South Africa) on two occasions, including the range of engagements experienced on-site, as well as the long-term collaborations that have continued. She will highlight the importance of building relationships and mutual trust, and explore the benefits arising from these visits. Her discussion will also draw on her experiences as a visiting scholar in other countries. (10 minutes). 


\section{Experiences as a visiting scholar in Ethiopia. Daniel Alemneh}

Alemneh will reflect on his Fulbright Scholar experience in Ethiopia. The Fulbright Scholar program plays a significant role in contributing to the capacity of host institutions. In addition to the formal teaching and research activities, Alemneh participated in strategic planning initiatives, and served on committees and review boards. He also facilitated local researchers' participation in international partnership programs. Alemneh will discuss how such partnerships also provide benefits to sending institutions in multiple ways, ranging from linking faculty members and students through various collaborative projects to developing a memorandum of understanding (MOU) or other formal agreements that facilitate international collaborations and engagements. (10 minutes).

Managing your expectations as a visiting professor to Africa nations. Abebe Rorissa

The presentation will identify things to expect overall and the need for adjusting your expectations and demands when you volunteer for or are invited to participate in a visiting professor program in Africa. The presentation draws on Rorissa's experiences as a visiting scholar in Ethiopia and other positions in Lesotho and Namibia. (10 minutes).

Engagement with the audience. ( 30 minutes)

After the presentations, the moderator and panelists will engage with the face-to-face and remote audiences, inviting them to share their ideas, initiatives, experiences, concerns and opportunities with respect to north-south collaboration and exchange programs. Audience members will be provided the option of submitting questions and comments online, and these will be shared anonymously during the panel discussion. Initial questions to stimulate the discussion include:

1. If you work in a developing country and have participated in a north-south collaboration or hosted a visiting scholar in your country as a host, please share:

- the two most important benefits you experienced as a result of your participation.

- the two most important things you learned during the collaboration or during the visit that you wished you had known earlier.

2. If you work in a developed country and have participated in a visiting scholar program or collaboration in a developing country or elsewhere, please share:

- the two most important benefits you experienced as a result of your participation.

- the two most important things you learned during your visit or during the collaboration that you wished you had known earlier.

3 . Is there a scholarly exchange program you wish to briefly introduce to the audience?

4. If you have not participated in a north-south collaboration or scholarly exchange program:

- what have been the two main barriers to participation?

- what two additional pieces of information, resources and/or incentives would you like to have before you commit to an exchange program or collaboration?

5. How could ASIS\&T assist in facilitating north-south scholarly exchanges and collaborations?

At the conclusion of the session, the moderator will summarize the outcomes of the panel discussions ( 2 minutes).

\section{EXPECTED OUTCOMES}

By the end of the panel discussion the audience will have increased their knowledge regarding the opportunities, benefits, challenges, and preparatory details for north-south collaborations and scholarly exchange programs. The audience will have new contact information about north-south scholarly exchange programs. Ideas regarding ways ASIS\&T could facilitate north-south collaboration and exchanges will be generated.

\section{PANEL MEMBERS}

Diane H. Sonnenwald is Emerita Professor at the University College Dublin, Ireland. She currently conducts workshops teaching collaboration skills and strategies, and consults with CILIP and the European Commission. She has been a Distinguished Visiting Professor at National Taiwan Normal University and an Erasmus + Visiting Professor at the University of Osijek, Croatia. Diane has received 25 grants from international foundations, corporations and funding agencies and published over 130 publications. Her research has focused on 
interorganizational and interdisciplinary collaboration, and on the design and evaluation of emerging and future technologies. She served as ASIS\&T President in 2012, and in 2020 she was awarded the ASIS\&T Award of Merit.

Ina Fourie is a Full Professor and Head of the Department of Information Science, University of Pretoria, South Africa. Ina holds positions in the leadership of the ASIS\&T Executive Board and ISIC (Information Seeking in Context) Steering Committee. Ina has collaborated with researchers from Israel, UK, USA, Sweden and The Netherlands. Her research focuses on information behavior, especially health information behavior in cancer, palliative care, grief and bereavement, autoethnography, information literacy and more recently participatory design, Third Space and information sharing. She has been a visiting academic to the USA and New Zealand.

Jaya Raju is a Full Professor and Head of the Department of Knowledge and Information Stewardship at the University of Cape Town in South Africa. She is a specialist researcher and author in library and/or information science education and its epistemological implications for the discipline and for professional practice, particularly in the African developing context. She is Co-editor-in-Chief of Library Trends, the inaugural Co-editor of the ALISE Book Series on LIS education and research, and serves on the editorial advisory boards of several journals internationally. Raju is also Subject Chair (LIS and multidisciplinary journals) on the Scopus Content Selection \& Advisory Board and Co-Chair of IFLA's Building Strong LIS Education (BSLISE). Jaya Raju and her Department have hosted visiting scholars from the US and the UK, and she and her colleagues have also been hosted as visitors in Canada, the US and the UK.

Heidi Julien is a Professor in the Department of Information Science, University at Buffalo, USA and a Research Associate at the University of Pretoria, South Africa. She has been involved in ASIS\&T in a range of roles for over two decades. Heidi serves on the JASIS\&T Editorial Board, and several other journal editorial boards. She is also active in ALISE, serving as President in 2018-19, and she serves on the Steering Committee for ISIC (Information Seeking in Context). Heidi publishes primarily in the areas of information behavior, digital/information literacy, and research methods; she won the 2020 SIGUSE Award for Outstanding Contributions to Information Behavior. She has worked as a scholar in New Zealand, Canada and the USA, and has been honored to serve as a visiting scholar in South Africa, China, Australia and New Zealand, in addition to giving invited talks in several other countries.

Daniel Alemneh is the Director of the Digital Curation Unit at the University of North Texas Libraries and Adjunct Professor at the College of Information, University of North Texas. For the past 20 years, Alemneh has been actively involved in various professional activities including serving on the ASIS\&T Board of Directors. He was a 2019-2020 Fulbright Scholar at Addis Ababa University's College of Natural Science, School of Information Science, in Ethiopia.

Abebe Rorissa is Professor and Director of the School of Information Sciences at the University of Tennessee, Knoxville), USA. Prior to his current position, he worked in four countries as an educator and practitioner. He has consulted for academic institutions, national governments, and international organizations, including the United Nations. His research interests include multimedia information organization and retrieval, scaling of users' information needs/perceptions, use/acceptance/adoption and impact of information and communication technologies, and data analytics. Abebe was a Member-at-Large on the ASIS\&T Board of Directors and a member of the Board's Executive Committee.

\section{REFERENCES}

ASIS\&T (2020). ASIS\&T Strategic Plan 2020-2025, Retrieved from https://www.asist.org/about/about-asist/asiststrategic-plan-2020-2025/.

Beck, J. (1987). The visiting faculty program: A cornerstone in the development of the university center for healthsciences and services. Israel Journal of Medical Sciences, 23(9-10), 995-1003.

Beeler, W. H., et al. (2020). Visiting professorship in academic radiation oncology. International Journal of Radiation Oncology Biology Physics, 108(3), 824-829.

Boudreau, F. \& Waschke, K. (2015). Canadian Association of Gastroenterology visiting research professorship and visiting clinical professorship. Canadian Journal of Gastroenterology and Hepatology, 29(5), 258-258.

Byrne, M. W. (1998). Productive international faculty exchange: One Columbia University to Gothenburg University example. Journal of Advanced Nursing, 27(6), 1296-1304. 
Calhoun, L. G., et al. (1980). International exchange of faculty: Specific problems of implementation. Teaching of Psychology, 7(3), 185-186.

Dubinsky, T. J. (2014). International visiting professorships: My experience in South Africa. Ultrasound Quarterly, 30(1), 77-79.

European Union (n.d.). Erasmus+: EU programme for education, training, youth and sport. Retrieved from https://ec.europa.eu/programmes/erasmus-plus/node_en

Fulbright Commission. (n.d.). Fulbright U.S. Scholar Program. Retrieved from https://cies.org/

Garcia-Sanchez, P. et al. (2019). Social capital and knowledge sharing in academic research teams. International Review of Administrative Sciences, 85(1), 191-207.

Haussler, S. C., et al. (2003). Finnish students' perceptions of a visiting professor. Journal of Professional Nursing, 19(2), 99-105.

Sayyid, S. K., et al. (2019). Current trends among US diagnostic radiology visiting professor programs. Journal of the American College of Radiology, 16(5), 757-761.

Shah, B. A., et al. (2020). Collaboration, collegiality, and sharing of resources: benefits of a visiting professor exchange program in breast imaging. Journal of Breast Imaging, 2(5), 492-500.

Skandhan, A. \& Apodaca, K. D. (2020). Improving medical education and academic hospital medicine faculty development through a structured faculty exchange. Journal of General Internal Medicine, 35(SUPPL 1), 739740 .

Sonnenwald, D. H. (2003). Managing cognitive and affective trust in the conceptual R\&D organization. In M. Iivonen and M. Huotari (Eds.), Trust in Knowledge Management and Systems in Organizations (pp. 82-106). Hershey, PA: Idea Publishing.

Sonnenwald, D. H. (2005). Management of cognitive and affective trust to support collaboration in geographically distributed organizations and teams: An overview. In M. Khosrow-Pour (Ed.), Encyclopedia of Information Science and Technology (pp. 1864-1869). Hershey, PA: Idea Publishing.

Sonnenwald, D. H. (2007). Scientific collaboration. In B. Cronin (Ed), Annual Review of Information Science and Technology (ARIST), Vol. 41 (pp. 643-681). Medford, NJ: Information Today.

Stupak, R. J. (1979). Visiting professors and their failures. Bureaucrat, 8(2), $42-49$.

Tabata, M. M., et al. (2019). Trends in the inclusion of black and female surgeons in invited visiting professorships. Jama Surgery, 154(9), 878-879.

Windchief, S. \& Ryan, K. E. (2019). The sharing of indigenous knowledge through academic means by implementing self-reflection and story. Alternative-an International Journal of Indigenous Peoples, 15(1), 82-89.

Xue, M., et al. (2015). Chinese visiting scholars' academic socialization in US institutions of higher education: A qualitative study. Asia Pacific Journal of Education, 35(2), 290-307. 